\title{
Particulate matter (PM) episodes at a suburban site in Hong Kong: evolution of PM characteristics and role of photochemistry in secondary aerosol formation
}

\author{
Yi Ming Qin ${ }^{1}$, Yong Jie Li $^{2}$, Hao Wang ${ }^{3}$, Berto Paul Yok Long Lee ${ }^{3}$, Dan Dan Huang ${ }^{1}$, and Chak Keung Chan ${ }^{1,3,4}$ \\ ${ }^{1}$ Department of Chemical and Biomolecular Engineering, Hong Kong University of Science and Technology, \\ Hong Kong, China \\ ${ }^{2}$ Department of Civil and Environmental Engineering, Faculty of Science and Technology, University of Macau, Taipa, \\ Macau, China \\ ${ }^{3}$ Division of Environment, Hong Kong University of Science and Technology, Hong Kong, China \\ ${ }^{4}$ School of Energy and Environment, City University of Hong Kong, Hong Kong, China
}

Correspondence to: Chak Keung Chan (chak.k.chan@ cityu.edu.hk) and Yong Jie Li (yongjieli@umac.mo)

Received: 17 May 2016 - Published in Atmos. Chem. Phys. Discuss.: 18 May 2016

Revised: 11 October 2016 - Accepted: 14 October 2016 - Published: 15 November 2016

\begin{abstract}
Episodes with high concentrations of particulate matter (PM) across the seasons were investigated during four 1-month campaigns at a suburban site in Hong Kong. Highresolution time-of-flight aerosol mass spectrometer (HRToF-AMS) measurements revealed that both regional transport and secondary formation contributed to high PM levels during the episodes at this site. Based on distinct meteorological conditions, episodes were categorized into three types: liquid water content (LWC), solar irradiance (IR), and long-range transport (LRT). Despite the difference in meteorological conditions, all episodes were characterized by a high fraction of sulfate (45-56\%) and organics (23-34\%). However, aerosols in LWC episodes were less aged, consisting of the lowest fraction of secondary organic aerosol (SOA) and the highest fraction of small particles. Large particles mixed internally while freshly formed small particles mixed externally in LWC episodes. Aerosols in LRT episodes, by contrast, were the most aged and consisted of the highest proportion of low-volatility oxygenated organic aerosol (LVOOA) and the lowest proportion of small particles. Both small and large particles mixed externally in LRT episodes. The highest proportion of semi-volatile oxygenated organic aerosol (SVOOA) and a medium proportion of small particles were observed in IR episodes. Both small and large particles were likely externally mixed during IR episodes. Furthermore, aerosols experienced the most dra-
\end{abstract}

matic size increase and diurnal variation, with a time lag between SVOOA and LVOOA and a gradual increase in carbon oxidation state $\left(\overline{\mathrm{OS}}_{\mathrm{c}} \approx 2 \times \mathrm{O}: \mathrm{C}-\mathrm{H}: \mathrm{C}\right)$. Five out of 10 episodes were of the IR type, further reflecting the importance of this type of episode. The evolution of aerosol components in one particular episode of the IR type, which exhibited a clear land-sea breeze pattern, was examined in detail. Sulfate and SOA due to photochemical aging were very efficiently produced during the course of $6 \mathrm{~h}$. The "lessoxidized" SOA (SVOOA) was initially formed at a higher rate than the "more-oxidized" SOA (LVOOA). The SVOOA transformed to LVOOA at the later stage of photochemical aging. This transformation was further supported by mass spectral analysis, which showed an increase in the most oxidized ion $\left(\mathrm{CO}_{2}^{+}\right)$and decreases in moderately oxidized ones $\left(\mathrm{C}_{2} \mathrm{H}_{3} \mathrm{O}^{+}, \mathrm{C}_{3} \mathrm{H}_{3} \mathrm{O}^{+}\right.$and $\left.\mathrm{C}_{3} \mathrm{H}_{5} \mathrm{O}^{+}\right)$. By measuring the physical and chemical properties of PM in a highly timeresolved manner, the current study was able to demonstrate the dynamic and complex nature of PM transformation during high-PM episodes.

\section{Introduction}

Hong Kong and the rest of the Pearl River Delta (PRD) in China have been battling air pollution episodes as a result 
of rapid economic development and urbanization in the region (Ho et al., 2003; Zhong et al., 2013). Meteorological conditions may govern the regional and long-range transport of air pollutants to Hong Kong. For example, northerly winds can bring pollutants from the inland areas to Hong Kong, and have been suggested to be responsible for regional air pollution events in winter (Fang et al., 1999; Huang et al., 2009; X. H. H. Huang et al., 2014). The majority of earlier studies used filter sampling with a low time resolution of hours to days and so were unable to track the temporal chemical transformation in high-particulate-matter (PM) episodes. This limitation has hindered our understanding of the dynamic nature of PM undergoing rapid chemical transformations. Such chemical transformation can occur within short time periods (e.g., within a day), and so do the other changes in physicochemical properties such as hygroscopic and optical properties. High-time-resolution chemical characterization techniques, for example the Aerodyne high-resolution time-of-flight aerosol mass spectrometer (HR-ToF-AMS), offer a temporal resolution of a few minutes. These techniques can thus provide valuable information on rapid changes in the PM composition, facilitating more detailed analysis of pollution events (Decarlo et al., 2006). HR-ToF-AMS measurements also give the size distributions of components (DeCarlo et al., 2008; Lee et al., 2013b). These data can reveal the origin, formation and atmospheric processing mechanisms of PM (Seinfeld and Pandis, 2006; Shiraiwa et al., 2013), but they remain under-utilized in most aerosol mass spectrometer (AMS) studies.

Secondary formation has been recognized as an important route leading to high PM concentrations worldwide (R. Zhang et al., 2015) and is the main culprit for haze episodes in cities across China (R.-J. Huang et al., 2014). Secondary organic aerosol (SOA) has been shown to dominate over primary organic aerosol (POA) after a few hours of photochemical aging, for instance, in Mexico City (Decarlo et al., 2010; Volkamer et al., 2006), Pasadena (Hayes et al., 2013) and Tokyo (Takegawa et al., 2006). Semi-volatile oxygenated organic aerosol (SVOOA), which serves as a proxy for less-oxidized SOA, has been shown to transform to low-volatility oxygenated organic aerosol (LVOOA), which serves as a proxy for more-oxidized SOA, in laboratory experiments (Alfarra et al., 2012; Jimenez et al., 2009). Such a transformation process may contribute substantially to the accumulation of PM, leading to episodic events that are frequently observed in the fast-developing city clusters in China (Huang et al., 2012; Y. W. Zhang et al., 2015).

We conducted four 1-month campaigns in each of the four seasons at the Hong Kong University of Science and Technology (HKUST) Air Quality Research Supersite (AQRS) from May 2011 to February 2012 using an Aerodyne HRToF-AMS for non-refractory $\mathrm{PM}_{1}$ (PM with aerodynamic diameter less than $1 \mu \mathrm{m}$ ). In our previous studies, we found that photochemical oxidation during a haze episode and aqueousphase reactions during two foggy periods both led to a high degree of oxygenation of organics due to aging in gas phase and/or aqueous phase with substantial SOA formation (Lee et al., 2013a; Li et al., 2013). In spring and summer, SOA, with abundant SVOOA, was more likely to form locally. The oxygen-to-carbon atomic ratio $(\mathrm{O}: \mathrm{C})$ and average carbon oxidation state $\left(\overline{\mathrm{OS}}_{\mathrm{c}}\right)$ peaked in the afternoon in spring and summer (Li et al., 2015). In autumn and winter, LVOOA dominated in SOA. The O:C ratio and $\overline{\mathrm{OS}}_{\mathrm{c}}$ showed little diurnal variation. Huang et al. (2015) estimated the contents of organic sulfur compounds in Hong Kong in September 2011. They highlighted the importance of both aqueousphase processing and regional influence for the formation of organic sulfur compounds. Closure analysis was performed between the PM hygroscopicity measured by a hygroscopic tandem differential mobility analyzer (HTDMA) and chemical composition measured by an HR-ToF-AMS and a constant growth factor of 1.18 for organics was found to be adequate for a good closure, given the dominant contribution of the very hygroscopic sulfate at this suburban site (Cheung et al., 2016; Yeung et al., 2014). Meng et al. (2014) found that the aerosol hygroscopic parameter $(k)$ decreased with an increasing organic-to-inorganic volume ratio. Furthermore, the concentration of cloud condensation nuclei $(\mathrm{CCN})$ was found to be more sensitive to the mixing state and hygroscopicity of the particles at a supersaturation ratio of $0.70 \%$ and $0.15 \%$, respectively.

The above studies primarily focused on the analysis of campaign-average scenarios, without specifically looking at episodic events that occurred during the campaign. In the current study, we investigated the chemical transformation and size evolution of secondary aerosols in high-PM episodes across the four seasons. Specifically, we examined in detail the photochemical evolution in a particular episode in which local influences were dominant. Results from the current study reveal the rapid evolution of secondary aerosols and are relevant to other megacities with large precursor input and high photochemical activity.

\section{Experimental section}

\subsection{Sampling site and measurements}

The sampling periods were from 25 April to 1 June 2011 (spring), from 1 to 29 September 2011 (summer), from 28 October to 15 December 2011 (autumn), and from 19 January to 1 March 2012 (winter). HR-ToF-AMS measurements were conducted at the HKUST AQRS $\left(22^{\circ} 20^{\prime} \mathrm{N}, 114^{\circ} 16^{\prime} \mathrm{E}\right)$, which sits on the hillside of Clear Water Bay on the east coast of Hong Kong, which has a relatively low population density. There is little local emission around the site. Two minor local sources include Clear Water Bay Road and a small student canteen. The Clear Water Bay Road is located outside of the campus and has mild traffic. The student canteen within $200 \mathrm{~m}$ of the site, which operates only from 18:00 LT (lo- 
cal time) until midnight. The HR-ToF-AMS operating procedure, data analysis and species determination have been discussed in Lee et al. (2013a), Li et al. (2015) and Huang et al. (2015). Briefly, the AMS was operated alternatively between the $\mathrm{V}+\mathrm{PToF}$ combined mode and the $\mathrm{W}$ mode for 5 min each. A collection efficiency of 0.5 was employed for measurements at this site, where the particles have overwhelmingly dominant sulfate content (Aiken et al., 2009; Li et al., 2013). Concentrations of methanesulfonic acid (MSA) and organosulfates (OSs) were estimated by combining the $\mathrm{V}$-mode data for total concentrations and the $\mathrm{W}$-mode data for high-resolution mass spectral analysis for specific ions (Huang et al., 2015). Mass spectra of organic sulfur compounds were obtained from standards in laboratory experiments to support the W-mode data analysis (Huang et al., 2015). We further calculated the particle liquid water content (LWC) by applying E-AIM II (Clegg et al., 1998) to explore the effects of aqueous processing on $\mathrm{PM}_{1}$ composition. Gaseous species $\left(\mathrm{CO}, \mathrm{CO}_{2}, \mathrm{SO}_{2}, \mathrm{NO}, \mathrm{NO}_{2}\right.$, and $\left.\mathrm{O}_{3}\right)$ were measured with standard gas analyzers (Teledyne API). Volatile organic compounds (VOCs) were measured by gas chromatography (Synspec GC955). Meteorological parameters were measured by an automatic weather station mounted on a tower right next to the supersite. Particle hygroscopicity and size distribution measurements have previously been taken with a HR-ToF-AMS at this site (Cheung et al., 2015; Man et al., 2015; Meng et al., 2014; Yeung et al., 2014), and direct reference to the resulting publications will be made where necessary.

\subsection{Data analysis}

\subsubsection{Criteria for an episodic event}

The total non-refractory $\mathrm{PM}_{1} \quad\left(\mathrm{NR}-\mathrm{PM}_{1}\right)$ concentration showed little seasonal variation, with monthly averages ranging from 14.3 to $15.9 \mu \mathrm{g} \mathrm{m}^{-3}$ as reported by Li et al. (2015). In this work, we defined episodic events according to the following criteria: (1) lasting for at least $24 \mathrm{~h}$, (2) daily NR$\mathrm{PM}_{1}$ average mass concentration exceeding $15 \mu \mathrm{g} \mathrm{m}^{-3}$ (overall monthly averaged concentration), and (3) maximum concentration exceeding $30 \mu \mathrm{g} \mathrm{m}^{-3}$. According to these criteria, 10 episodic events were identified in the campaigns as shown in Fig. S1 in the Supplement.

\subsubsection{Source apportionment}

Following the results in $\mathrm{Li}$ et al. (2015), $72 \mathrm{~h}$ backward air trajectory analysis and positive matrix factorization (PMF) analysis were performed. Briefly, the back trajectory analysis was run at an elevation of $300 \mathrm{~m}$ using the HYSPLIT-4.8 (Hybrid Single-Particle Lagrangian Integrated Trajectory) model developed by NOAA/ARL (U.S. National Oceanic and Air Administration/Air Resources Laboratory). We classified air masses affecting Hong Kong into long-, medium-, and short-range transport patterns for transport distances of $1000 \mathrm{~km}$, between 500 and $1000 \mathrm{~km}$, and less than $500 \mathrm{~km}$, respectively (Su et al., 2015).

For PMF analysis, a four-factor solution with hydrocarbon-like organic aerosol (HOA), cooking organic aerosol (COA), SVOOA, and LVOOA was adopted as in Li et al. (2015). During episodic events, HOA and COA contributed insignificantly (less than 6 and $5 \%$, respectively) to total organic aerosol (OA). Since we are interested in SOA transformation, HOA and COA were combined into one POA factor in the following discussion.

\subsubsection{Size distribution}

Size distributions of aerosol species are obtained with the HR-ToF-AMS when a set of pre-selected $m / z$ is scanned as a function of the particle time of flight. We focus on the size distribution analysis of sulfate and organics because of their

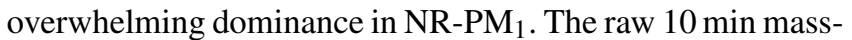
size distributions of organics and sulfate during the episodic events were averaged over various time periods pertaining to the resolution (e.g., 2 or $1 \mathrm{~h}$ ). The average size distributions were then fitted by the peak-fitting tool Multipeak Fit V2 provided by Igor Pro (Wavemetrics) using two lognormal peaks. The peaks were chosen such that the fit residuals were minimized. The two fitted peaks of the size distributions will hereafter be referred to as the small particle mode and the large particle mode. Fitting examples can be found in Fig. S2. We will focus on the most important fitting parameters: the particle mass-mode diameter (vacuum aerodynamic diameter, $D_{\text {va }}$ ) indicating the shift in particle size and the integrated peak areas of the small particle mode and the large particle mode indicating the changes in mass concentrations of larger or smaller particles.

\subsubsection{Photochemical age}

The photochemical age is useful for studying the extent of photochemical processing in an air mass. One way to estimate the photochemical age $(\Delta t)$ is by the ratio of a less reactive hydrocarbon to a more reactive one (Kleinman, 2003):

$\Delta t=\frac{\operatorname{Ln}\left(\frac{C_{j}}{C_{i}} \times \frac{C_{i 0}}{C_{j 0}}\right)}{\left(k_{i}-k_{j}\right)[\mathrm{OH}]}$,

in which $C_{i}$ and $C_{j}$ are concentrations of hydrocarbons $i$ and $j$ at time $t$, whereas $C_{i 0}$ and $C_{j 0}$ are concentrations of hydrocarbons $i$ and $j$ at time 0 . The symbols $k_{i}$ and $k_{j}$ are their respective rates of reaction with hydroxyl radicals $(\mathrm{OH})$. Hofzumahaus et al. (2009) reported a high average $\mathrm{OH}$ concentration of $15 \times 10^{6}$ molecules $\mathrm{cm}^{-3}$ around noon in the PRD region, much higher than model predictions. Zhou et al. (2014) used an $\mathrm{OH}$ concentration of $5.2 \times 10^{6}$ molecules $\mathrm{cm}^{-3}$ in their calculation of photochemical age in the PRD region. Lacking definitive 
estimates, we used a conservative $\mathrm{OH}$ concentration of $1.5 \times 10^{6}$ molecules $\mathrm{cm}^{-3}$ (Hayes et al., 2013; Mao et al., 2009) for the discussion of oxidation trends in this study. The ratio of benzene to toluene has been widely used (El Haddad et al., 2013) because of their similar emission sources and significantly different rates of reaction with $\mathrm{OH}$ radicals $\quad\left(k_{\text {benzene-OH }}=1.23 \times 10^{-12} \mathrm{~cm}^{3}\right.$ molecule $^{-1} \mathrm{~s}^{-1}$; $k_{\text {toluene-OH }}=6.0 \times 10^{-12} \mathrm{~cm}^{3}$ molecule ${ }^{-1} \mathrm{~s}^{-1}$ at $298 \mathrm{~K}$ ) (Atkinson Roger, 2000). Because toluene reacts more rapidly with $\mathrm{OH}$ radicals than does benzene, it is depleted more quickly, resulting in higher benzene/toluene ratios in aged air masses. However, the photochemical age can deviate when fresh pollutants are added to an aged air mass. Since fresh pollutants were insignificant after 10:00 LT (i.e., no significant peaks of benzene and toluene after 10:00 LT; see Fig. S3), we set the start time at 10:00 LT for the discussion of photochemical aging.

\section{Results and discussion}

\subsection{Meteorological conditions and classification of episodes}

Table 1 summarizes the meteorological conditions, $\mathrm{PM}_{1}$ concentrations, and the estimated LWC in the 10 high-PM episodes. All of the episodes involved air masses that originated over East Asia from the north, northeast or northwest of Hong Kong and swept over part of the PRD region before reaching the site. Seven of the 10 episodes (E1E7) were characterized by medium-range trajectories and the other three (E8-E10) by long-range trajectories. The individual trajectories are shown in Fig. S4. E1 and E2 had much lower solar irradiance (IR) but higher LWC than the other episodes, which distinguished them from the other mediumrange transport episodes. Thus, E1 and E2 were categorized as episodes of the LWC type (medium-range transport with high LWC and low IR) and the other medium-range transport episodes as episodes of the IR type (medium-range transport with high IR and low LWC). Li et al. (2013) referred to E1 and E2 as foggy episodes, while Li et al. (2013) and Lee et al. (2013a) referred to E3 as a hazy episode. The longrange transport episodes might be less associated with the local site-specific conditions and were categorized as episodes of the LRT type.

High concentrations of PM can have a number of causes, including enhanced primary emissions (Ji et al., 2014), concentrating effects due to a decrease in the height of the planetary boundary layer (Petäjä et al., 2016), regional transport (Huang et al., 2009), and active secondary formation (Hayes et al., 2013). Local primary emissions were not very significant at this site, as can be seen from the low contribution of POA (less than $6 \%$ ) throughout the whole campaign. As an indicator for primary PM, elemental carbon (EC) concentrations in $\mathrm{PM}_{2.5}$ filter sampling at this site from March 2011 to
February 2012 were also found to be low throughout the year $\left(0.86 \pm 0.53 \mu \mathrm{g} \mathrm{m}^{-3}\right)$ (X. H. H. Huang et al., 2014). Boundary layer dynamics on the high-PM days can be a factor affecting PM concentration, but the effects were likely minimal as the highest concentration was usually observed during the day at higher mixing heights (Fig. S5). Therefore, regional transport and active secondary formation would be the most probable causes for the episodic events of high PM concentrations at this suburban site. More detailed meteorological conditions with chemical characteristics in each episode can be found in Fig. S5.

As is apparent from Table 1, the occurrence of different types of episodes exhibits a seasonal trend. LWC episodes occurred only in spring and LRT episodes only in winter, while IR episodes took place in spring, summer and autumn. This result is consistent with previous results (Huang et al., 2009) in that the frequency of high-PM days in Hong Kong had a strong seasonal variation. In winter, the overwhelming northerly wind brings pollutants via long-range transport (Fang et al., 1999). In spring, foggy days with high PM levels are common due to the moisture-laden air masses coming in from the sea and aqueous-phase processing of particulate species (Li et al., 2013). In summer and autumn, however, hazy days are mainly due to high photochemical activities in this subtropical area, resulting in the formation of secondary aerosols (Hu et al., 2008; Zhou et al., 2014).

\subsection{Chemical characteristics of high-PM episodes}

Figure 1 shows the chemical constituents of NR-PM $\mathrm{PM}_{1}$ in the three types of episodes. It is apparent that sulfate dominated in all types of episodes. In Hong Kong, sulfate is largely regarded as a major regional pollutant with little spatial variability, as in the rest of the PRD (Hagler et al., 2006; Louie et al., 2005). Nitrate contributed less than $4 \%$ in LWC episodes and IR episodes but more than $7 \%$ in LRT episodes. As LRT episodes occurred in wintertime, the higher nitrate concentration was likely driven by gas-particle partitioning of ammonium nitrate to the particle at low temperatures (Seinfeld and Pandis, 2006). Using the PMF-resolved SVOOA and LVOOA as proxies for less-oxidized and more-oxidized SOA respectively (Zhang et al., 2011), more details of OA can be revealed. SVOOA had higher contributions in IR episodes, while LVOOA contributed roughly twice as much as SVOOA did in LRT episodes, because the air mass was already quite aged when it reached the site. LVOOA and SVOOA made similar contributions in LWC episodes.

Figure 2 shows the diurnal variations of the NR-PM species, PMF-resolved organic factors, and $\mathrm{O}_{x}\left(\mathrm{O}_{3}+\mathrm{NO}_{2}\right)$ in these three types of episodes. SVOOA and LVOOA as well as $\mathrm{O}_{x}$ increased during the day in IR episodes, with a time lag between SVOOA and LVOOA. A similar time lag was also observed between SVOOA and LVOOA in the Yangtze River Delta (YRD), another fast-developing region of China (Huang et al., 2012). These delays may be the result of con- 
Table 1. Synopsis of meteorological conditions of high-PM episodes.

\begin{tabular}{|c|c|c|c|c|c|c|c|c|c|}
\hline Episode & Season & Date & $\begin{array}{l}\text { Air mass } \\
\text { origin }\end{array}$ & $\begin{array}{r}\text { Wind speed } \\
\left(\mathrm{m} \mathrm{s}^{-1}\right)\end{array}$ & $\begin{array}{r}\text { Solar } \\
\text { irradiance } \\
\left(\mathrm{w} \mathrm{m}^{-2}\right)\end{array}$ & $\begin{array}{r}\text { Liquid water } \\
\text { content } \\
\left(\mu \mathrm{g} \mathrm{m}^{-3}\right)\end{array}$ & $\begin{array}{r}\mathrm{PM}_{1} \\
\left(\mu \mathrm{g} \mathrm{m}^{-3}\right)\end{array}$ & $\begin{array}{l}\mathrm{PM}_{1} \max \\
\left(\mu \mathrm{g} \mathrm{m}^{-3}\right)\end{array}$ & Type \\
\hline E1 & Spring & 28-30 Apr & $\mathrm{M}-\mathrm{R}^{\mathrm{a}} / \mathrm{NE}^{\mathrm{b}}$ & $0.7 \pm 0.4$ & $41 \pm 67$ & $47.1 \pm 15.9$ & $25.5 \pm 3.1$ & 33.1 & LWC \\
\hline E2 & Spring & 14-16 May & $M-R^{a} / N E^{b}$ & $1.1 \pm 0.8$ & $27 \pm 61$ & $38.6 \pm 14.5$ & $18.8 \pm 6.4$ & 32.4 & LWC \\
\hline E3 & Spring & 27-29 May & $\mathrm{M}-\mathrm{R}^{\mathrm{a}} / \mathrm{NE}^{\mathrm{b}}$ & $0.9 \pm 0.8$ & $184 \pm 263$ & $19.3 \pm 9.2$ & $28.4 \pm 12.6$ & 64.1 & IR \\
\hline $\mathrm{E} 4$ & Summer & $2 \mathrm{Sep}$ & $\mathrm{M}-\mathrm{R}^{\mathrm{a}} / \mathrm{NW}^{\mathrm{b}}$ & $0.5 \pm 0.4$ & $111 \pm 163$ & $20.0 \pm 3.1$ & $22.5 \pm 6.1$ & 33.7 & IR \\
\hline E5 & Summer & 20-24 Sep & $\mathrm{M}-\mathrm{R}^{\mathrm{a}} / \mathrm{NE}^{\mathrm{b}}$ & $2.2 \pm 0.5$ & $143 \pm 234$ & $14.9 \pm 4.6$ & $23.8 \pm 4.8$ & 35.9 & IR \\
\hline E6 & Autumn & $3 \mathrm{Nov}$ & $\mathrm{M}-\mathrm{R}^{\mathrm{a}} / \mathrm{NE}^{\mathrm{b}}$ & $1.3 \pm 0.5$ & $174 \pm 271$ & $12.8 \pm 5.9$ & $15.6 \pm 6.2$ & 30.0 & IR \\
\hline E7 & Autumn & $13-15$ Nov & $\mathrm{M}-\mathrm{R}^{\mathrm{a}} / \mathrm{NE}^{\mathrm{b}}$ & $1.2 \pm 0.5$ & $150 \pm 221$ & $19.4 \pm 7.0$ & $23.4 \pm 7.0$ & 45.2 & IR \\
\hline E8 & Winter & 24-25 Nov & $\mathrm{L}-\mathrm{R}^{\mathrm{a}} / \mathrm{NE}^{\mathrm{b}}$ & $1.6 \pm 0.5$ & $112 \pm 174$ & $14.1 \pm 6.6$ & $25.9 \pm 6.2$ & 38.6 & LRT \\
\hline E9 & Winter & $8 \mathrm{Feb}$ & $\mathrm{L}-\mathrm{R}^{\mathrm{a}} / \mathrm{N}^{\mathrm{b}}$ & $2.2 \pm 0.6$ & $49 \pm 74$ & $27.8 \pm 2.8$ & $29.7 \pm 8.1$ & 41.6 & LRT \\
\hline E10 & Winter & 18-19 Feb & $\mathrm{L}-\mathrm{R}^{\mathrm{a}} / \mathrm{NE}^{\mathrm{b}}$ & $1.5 \pm 0.6$ & $104 \pm 170$ & $16.0 \pm 5.3$ & $25.5 \pm 9.4$ & 64.9 & LRT \\
\hline
\end{tabular}

${ }^{a}$ Range of air mass origin: medium range (M-R); long range (L-R). ${ }^{b}$ Direction of air mass origin: northeast (NE); northwest(NW); north (N).

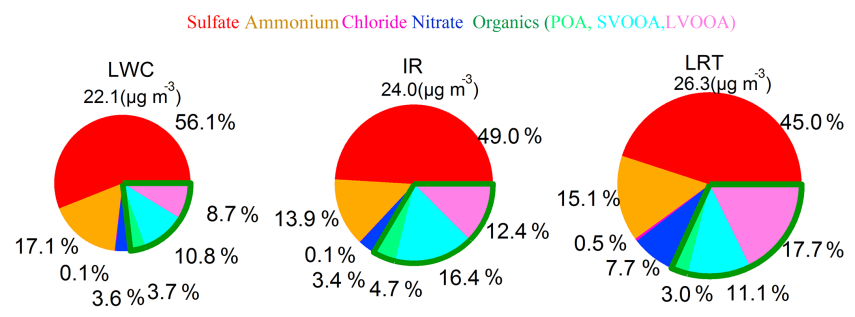

Figure 1. Chemical constituents NR-PM 1 in LWC, IR and LRT episodes (LWC: medium-range transport with high LWC and low IR; IR: medium-range transport with high IR and low LWC; LRT: long-range transport).

versions from SVOOA to LVOOA in the afternoon. We explore such a possibility in Sect. 3.6. SVOOA and LVOOA both exhibit flat diurnal patterns in LWC episodes and LRT episodes.

Elemental analysis of $\mathrm{OA}$ (ratios of $\mathrm{H}: \mathrm{C}, \mathrm{O}: \mathrm{C}, \mathrm{N}: \mathrm{C}$, $\mathrm{S}: \mathrm{C}$ and $\mathrm{OM}: \mathrm{OC}$ ) from the high-resolution mass spectra provides useful information to assess OA evolution. Recently, Canagaratna et al. (2015) used an updated ("Improved-Ambient") method to estimate $\mathrm{O}: \mathrm{C}$ and $\mathrm{H}: \mathrm{C}$ ratios, and reported $27 \%$ higher $\mathrm{O}: \mathrm{C}$ ratios and $11 \%$ higher $\mathrm{H}: \mathrm{C}$ ratios than those estimated using the original ("AikenAmbient") method. Recalculating the elemental ratios for the September dataset using the updated method shows little difference from those obtained by simply applying the respective factors of 1.27 and 1.11 to the $\mathrm{O}: \mathrm{C}$ and $\mathrm{H}: \mathrm{C}$ ratios (Fig. S6). Hence, the $\mathrm{O}: \mathrm{C}$ and $\mathrm{H}: \mathrm{C}$ ratios in this study were corrected by factors of 1.27 and 1.11 , respectively, with Aiken-Ambient values reported in our previous studies. In the Van Krevelen diagram (Heald et al., 2010; Ng et al., 2011) shown in Fig. 3a, data points for LWC episodes (blue) fall into a lower $\mathrm{O}: \mathrm{C}$ region than do the data points for IR (red) and LRT episodes (green). Although aqueous-
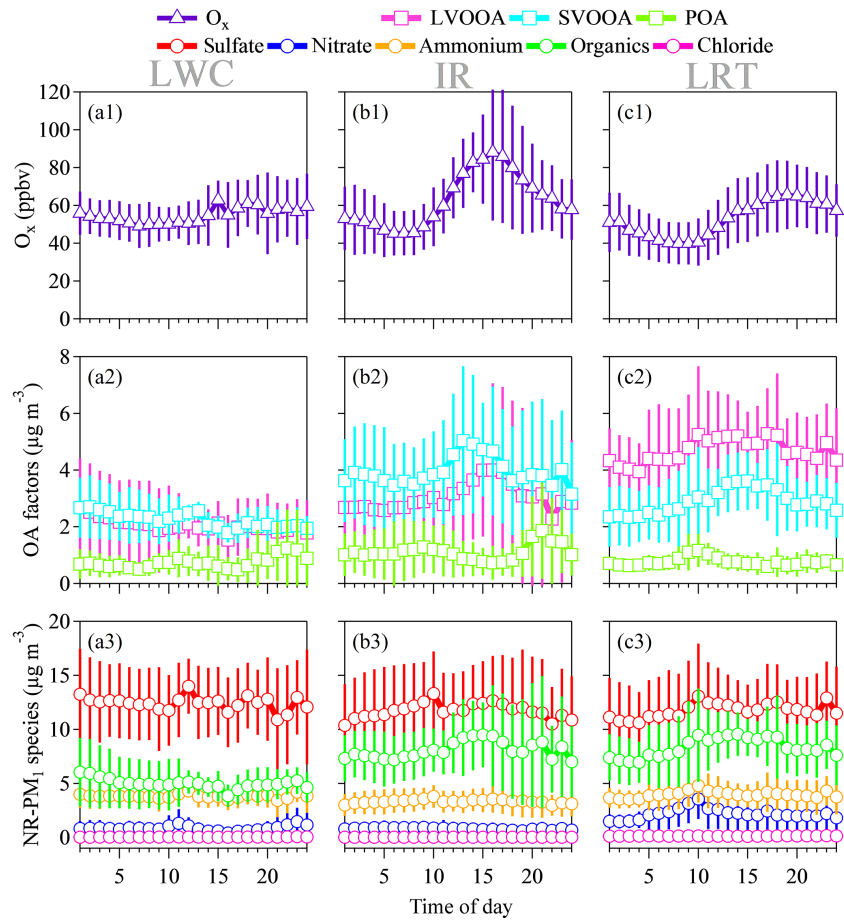

Figure 2. Summary of diurnal variations of the $\mathrm{PM}_{1}$ species, $\mathrm{PMF}-$ resolved organics and $\mathrm{O}_{x}$ in the three types of episodes. Means are shown as points and standard deviations as error bars.

phase processing might generate highly oxygenated organic compounds (Li et al., 2016; Mazzoleni et al., 2010; Zhao et al., 2013), sampling by the AMS was only limited to interstitial particles and a portion of very small fog droplets after drying. This can also lead to $\mathrm{O}: \mathrm{C}$ ratios lower than those in IR periods when most of the photochemically oxidized OA were effectively sampled. Even though data points for IR episodes and LRT episodes have similar slopes and intercepts 

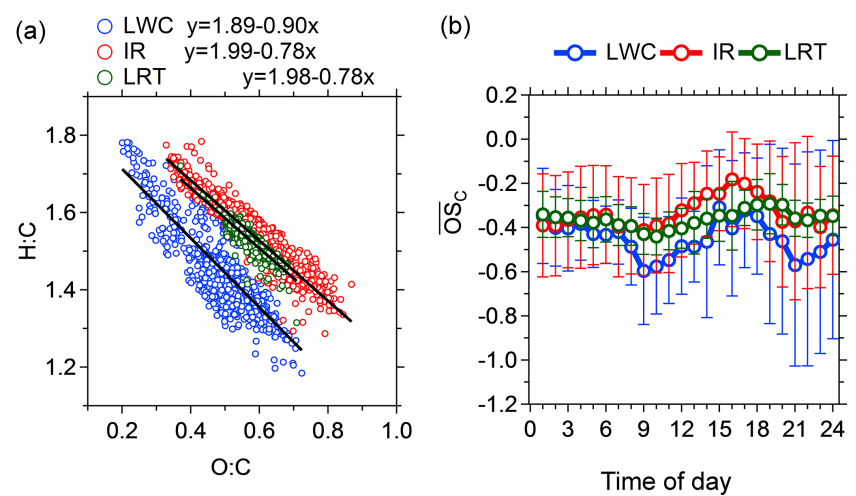

Figure 3. (a) Van Krevelen diagram for the three types of episodes and (b) diurnal variation in carbon oxidation state $\left(\overline{\mathrm{OS}}_{\mathrm{c}}\right)$. Means appear as circles with superimposed standard deviations.

in the Van Krevelen diagram, data points for IR episodes had a much wider spread. These trends are also reflected in the diurnal patterns of carbon oxidation state $\left(\overline{\mathrm{OS}}_{\mathrm{c}} \approx 2 \times \mathrm{O}: \mathrm{C}-\mathrm{H}\right.$ : C) (Kroll et al., 2011) in Fig. 3b. The $\overline{\mathrm{OS}}_{\mathrm{c}}$ diurnal pattern in LRT episodes was relatively flat, suggesting that oxidized organics were mostly transported to the site with minor in situ oxidation. The $\overline{\mathrm{OS}}_{\mathrm{c}}$ in IR episodes gradually increased from 09:00 until 15:00 LT. Similar trends were observed for $\mathrm{O}_{x}$, LVOOA and, to a lesser extent, SVOOA. With all these combined, we believe that the local photochemical processing of OA was more likely at play in IR episodes than the longrange transport of processed aerosols was.

\subsection{Size distributions of sulfate and organics}

Figure 4 shows the peak fitting results of the type-averaged size distributions of organics and sulfate mass. The massmode diameters $\left(D_{\mathrm{va}}\right)$ for both the small and large modes of organics and sulfate did not differ considerably across the episode types (differing by less than $5 \%$ ). Within each type of episode, sulfate had a smaller fraction of small particle mode than organics did, indicating that sulfate was relatively aged, while organics received contributions from local fresh emissions. LWC episodes received the largest contribution from small-mode sulfate because of some local influences, whereas LRT episodes received the smallest contribution with relatively few local activities. The oxidation mechanisms, however, might be different. Aqueous-phase oxidation may dominate in LWC episodes, while photochemical oxidation may dominate in IR episodes.

Various studies have analyzed the particle mixing state using single-particle instruments such as aerosol time-of-flight mass spectrometers (Healy et al., 2013, 2014; Yang et al., 2012) and single-particle aerosol mass spectrometers (Wang et al., 2015). Particle mixing state can also be inferred from particle size information obtained with the AMS. If the organics and sulfate are internally mixed (i.e., they exist in the same particle), their diameters should be strongly correlated with each other and their size should grow at a similar rate. The observed strong correlation and slope of unity (correlated in time and size) suggest that these species are likely internally mixed, although we cannot completely exclude the possibility of external mixing. On the other hand, if the mode diameters of sulfate and organics did not change coherently and exhibit a strong correlation with a slope close to unity, these particles were more likely externally mixed. Bahreini et al. (2003) have used such correlations in size to indicate the mixing states of species. In our study, the large-mode diameters of organics and sulfate were strongly correlated (Pearson's $R$ value equals 0.7 ) with a slope close to unity in LWC episodes (Fig. 5), suggesting that organics and sulfate were likely internally mixed in the large particles. However, these conditions of correlation and slope are necessary but not sufficient evidence for internal mixing. This internal mixing may occur during the process of local aqueous oxidation. In IR episodes, during which local photochemical oxidation may have a more obvious influence, larger particles do not mix well internally (poor correlation between the largemode diameters of organics and sulfate with Pearson's $R$ $\left.\left(R_{\mathrm{pr}}\right)=0.2\right)$. As discussed in Sect. 3.2, in IR episodes, organics showed a clear noontime peak associated with local photochemical activities, while sulfate was still mainly a regional pollutant. As a result, large particles of organics and sulfates were very likely to have been externally mixed during IR episodes. A good correlation $\left(R_{\mathrm{pr}}=0.7\right)$ with the slope deviating substantially from unity (slope $=0.5$ ) was observed in LRT episodes. As long-range transport was the dominant process causing high PM levels during LRT episodes, organics and sulfate would have been brought to the site together, so their large-mode diameters tend to be strongly correlated. However, they may have different origins and may also have undergone different aging processes during the course of long-range transport, and thus their mode diameters would be different. The correlations between the small-mode diameters of organics and sulfate were notably weaker, with $R_{\mathrm{pr}}=0.5$ in LWC episodes, $R_{\mathrm{pr}}=0.2$ in IR episodes, and $R_{\mathrm{pr}}=0.2$ in LRT episodes, suggesting that freshly formed small particles mixed externally.

As discussed earlier, there may be some local atmospheric processing of aerosols in LWC and IR episodes but not in LRT episodes. Therefore, we further explored the mechanisms underlying the atmospheric processing of LWC and IR episodes based on the size variations before and during episodic events. Figure 6 shows the particle mass-mode diameters and areas (concentrations) in the LWC and IR types of episodes. We obtained the percentage changes in mode diameters by comparing the smallest diameter before the episode and the largest diameter during the episode for each episode. These percentages in each episode were then averaged to obtain the percentage changes for each episode type. The results show that the changes in mode diameter were small in the LWC episodes: $-2.5 \%$ for smallmode organics, $+8.1 \%$ for large-mode organics, $+1.6 \%$ for 
Org small mode $\square$ Org large mode

Sulfate large mode $\square$ Sulfate small mode
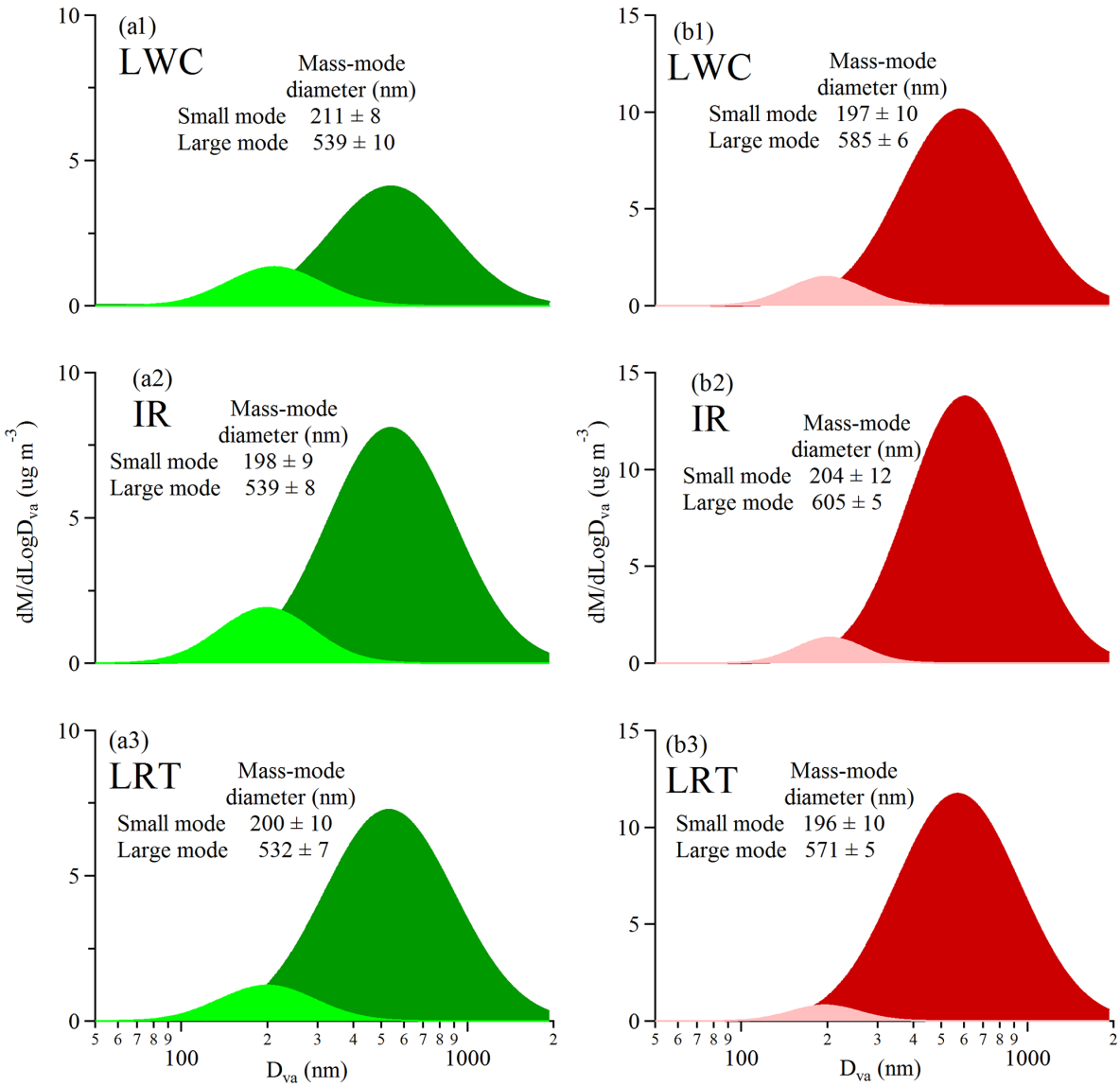

Figure 4. Bimodal lognormal fitting results of the size distributions of organics and sulfate during the three types of episodes. (a) Fitted small particle size mode and large particle size mode of organics during LWC, IR and LRT episodes. (b) Fitted small particle size mode and large particle size mode of sulfate during LWC, IR and LRT episodes.

small-mode sulfate, and $-3 \%$ for large-mode sulfate. In contrast, the changes in mode diameters were much more drastic in the IR episodes: $+51.3 \%$ for small-mode organics, $+40.5 \%$ for large-mode organics, $+45.4 \%$ for small-mode sulfate, and $+35.9 \%$ for large-mode sulfate. Furthermore, particle size usually increased more rapidly before the IR episodes (shaded in blue in Fig. 6) than during the episodes (shaded in orange). With fewer pre-existing particles before the episodes, particle growth - likely via condensation and reactive uptake of semi-volatile components - was more rapid than during the episodes. The number concentration is discussed in detail in the Supplement.

\subsection{Local photochemical formation and evolution of PM: a case study}

\subsubsection{Time series of species during the local photochemical episode}

Because of the high frequency of occurrence of IR episodes, we chose one IR episode (E4) to examine the evolution of the aerosols with photochemical oxidation. This particular episode (E4) was under the influence of a clear land-sea breeze pattern with weak winds (Fig. 7), a typical meteorological phenomenon that affects air pollution dynamics at this coastal city (Lee et al., 2013a). As can be seen from Fig. 7, the maximum wind speed was less than $2 \mathrm{~m} \mathrm{~s}^{-1}$, while the average wind speed was approximately $0.5 \mathrm{~m} \mathrm{~s}^{-1}$. The wind direction changed from northerly to easterly between 06:00 and 10:00 LT and remained easterly until 20:00 LT, when it changed clockwise from easterly back to northerly. Under such conditions, local photochemical activities can 
- Small-mode particles

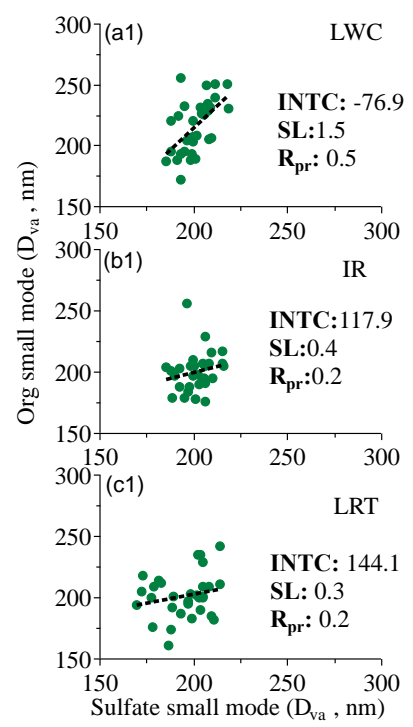

Large-mode particles

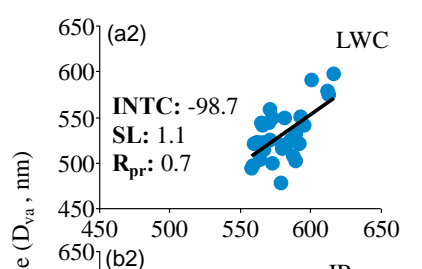

IR

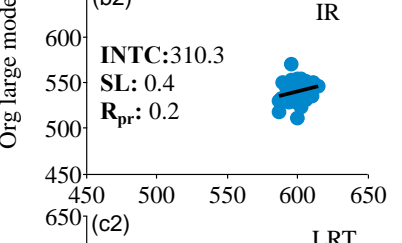

650 (c2) LRT

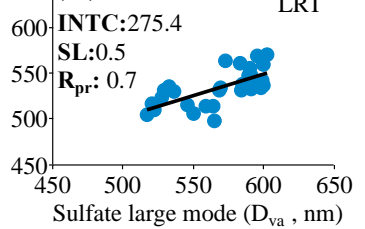

Figure 5. Scatter plots and linear least-squares fits of mass-mode diameters of organics and sulfate during the three different types of episodes. (a1, a2) Small and large mass-mode diameter of organics against sulfate during LWC episodes, (b1, b2) small and large massmode diameter of organics against sulfate during IR episodes, and (c1, c2) small and large mass-mode diameter of organics against sulfate during LRT episodes. INTC stands for intercept, SL stands for slope and $R_{\mathrm{pr}}$ stands for Pearson's $R$.

lead to effective production and accumulation of air pollutants. Time series of organics, sulfate, ammonium, nitrate, MSA, OS, PMF-resolved organic factors, some gaseous species, and meteorological parameters were analyzed. Most

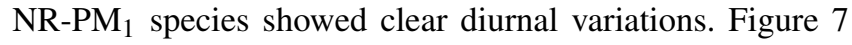
shows that organics increased from a roughly constant concentration of $10 \mu \mathrm{g} \mathrm{m}^{-3}$ at night until 09:00 LT to its highest concentration of $16.6 \mu \mathrm{g} \mathrm{m}^{-3}$ at 13:00 LT, while sulfate showed a mild increase at 06:00 LT and then a sharp increase at 10:30 LT to reach its highest concentration of $17.4 \mu \mathrm{g} \mathrm{m}^{-3}$ at 16:00 LT. They were overall consistent with the increasing trend of irradiance, a driver of photochemical activities, in the afternoon. Nitrate concentration was high $\left(2.5 \mu \mathrm{g} \mathrm{m}^{-3}\right)$ in the morning and started to decrease from 12:30 LT onwards, reaching $0.3 \mu \mathrm{g} \mathrm{m}^{-3}$ by $16: 00 \mathrm{LT}$, likely attributable to vertical dilution due to a rise in the height of the planetary boundary layer, or alternatively evaporation of ammonium nitrate at higher temperatures and lower RH values (Seinfeld and Pandis, 2006). Wind direction started to change at 20:00 LT, when all the NR-PM $M_{1}$ species were at their lowest concentrations. POA concentration increased from $2.5 \mu \mathrm{g} \mathrm{m}^{-3}$ at 00:00 LT to about $5 \mu \mathrm{g} \mathrm{m}^{-3}$ at 06:00 LT, which might be due to the lowering of the planetary boundary layer. Conversely, expansion of the boundary layer early in the morning could help disperse the POA. The increase in LVOOA lagged behind that in SVOOA. Starting from 06:00 LT, SVOOA con-

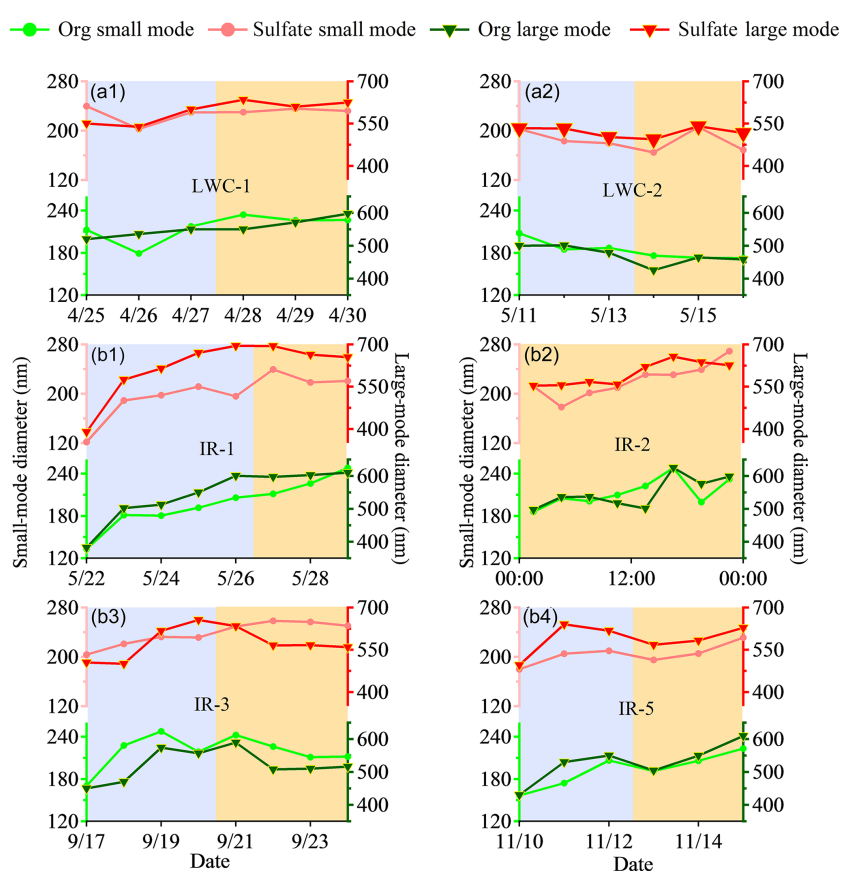

Figure 6. Variations in $24 \mathrm{~h}$ averaged size distributions of fitted mass-mode diameters of organics and sulfates during LWC episodes and IR episodes (shaded in orange) and several days before each episode (shaded in blue). For the episode that lasted only for a day (E4), $3 \mathrm{~h}$ averaged size distributions of fitted mass-mode diameters are shown instead. (a) LWC episodes and (b) IR episodes.

centration increased rapidly and peaked at approximately 13:00 LT, coinciding with the IR peak, possibly due to SOA formation. LVOOA gradually increased from 12:00 LT and peaked at 14:00 LT, similar to sulfate. The time lag suggests that some conversion from less-oxidized to more-oxidized SOA might have occurred in the afternoon. Evaporation at the elevated temperature of $30^{\circ} \mathrm{C}$ throughout the afternoon might also have led to the decrease in SVOOA, as with nitrate. The diurnal variation in MSA shows a noontime peak, consistent with the trend of irradiance. In contrast, OSs did not show a clear noontime peak, since OSs at this site were likely affected by inland transportation (Huang et al., 2015).

\subsubsection{Changes in size distribution}

As shown Fig. 8, before 06:00 LT, the size distributions of sulfate and organics were both dominated by a mass-mode diameter of 500 to $600 \mathrm{~nm}$. During 06:00-09:00 LT, a shoulder at $200 \mathrm{~nm}$ appeared in the size distribution of sulfate and in that of organics, indicating some fresh sulfate and organics were formed or emitted (possibly POA). As photochemical reactions proceeded (09:00-18:00 LT), the shoulder of $D_{\mathrm{va}}$ at $200 \mathrm{~nm}$ became weaker and the size distributions shifted to the larger end. It should be noted that, during the whole aging process, the size distributions of organics were broader than those of sulfate since organics were a mixture of nu- 


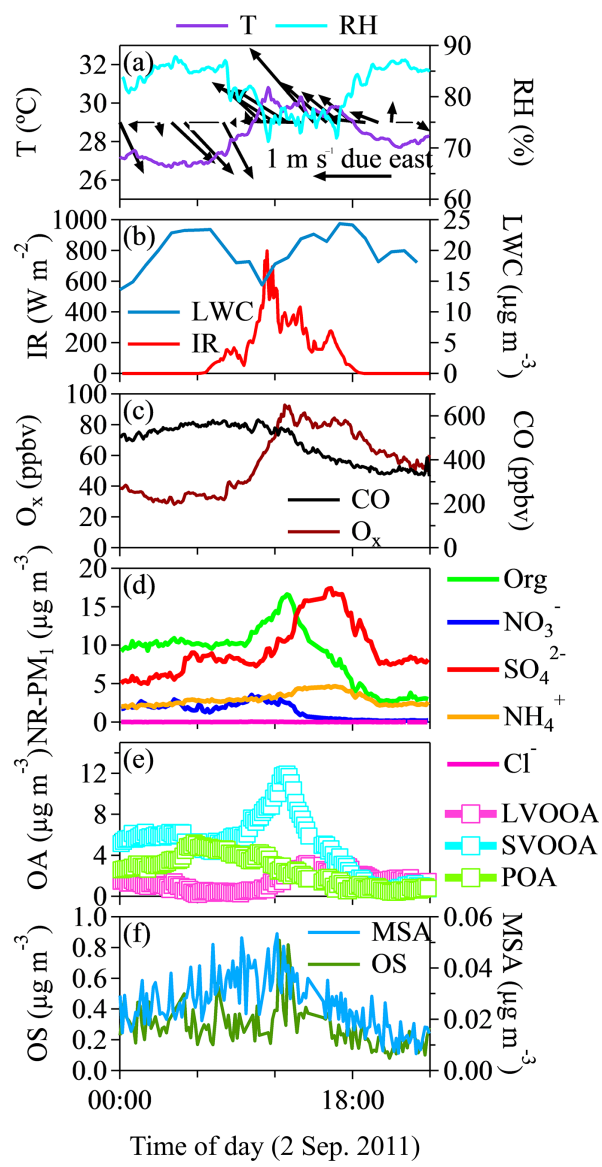

Figure 7. Time series of meteorological parameters, gaseous species, NR-PM 1 species and PMF-resolved organic factors in E4.

merous constituents from different primary sources and reaction products formed via different atmospheric processes. The shifts in size distribution suggest that secondary aerosol particles with sulfate and organics aged gradually and grew into larger particles.

\subsubsection{Photochemical production of secondary species}

We examine the daytime photochemical activity during E4 by looking at the $\mathrm{SO}_{2}$ oxidation and changes in the degree of oxygenation of particulate organics. The sulfur oxidation ratio (SOR) has been used to evaluate the extent of atmospheric oxidation of $\mathrm{SO}_{2}$ to sulfate (Squizzato et al., 2013; Wang et al., 2005). Figure $9 \mathrm{c}$ shows the increase in SOR from 0.2 at 09:00 LT to 0.7 at 18:00 LT, indicating an efficient conversion from $\mathrm{SO}_{2}$ to sulfate during daytime in this episode. Figure $9 \mathrm{~b}$ shows that the $\overline{\mathrm{OS}}_{\mathrm{c}}$ increased sharply near 11:00 LT. $\overline{\mathrm{OS}}_{\mathrm{c}}$ was high after 18:00 LT because most of the organics in PM had been converted to highly oxidized organic compounds during the aging process. Indeed, during this period, LVOOA was the dominant OA component (Fig. 7). The increases in SOR and $\overline{\mathrm{OS}}_{\mathrm{c}}$ coincided with the increase in the ratio of benzene to toluene (Fig. 9). The oxidation of sulfur species and organic
Sulfate Organics

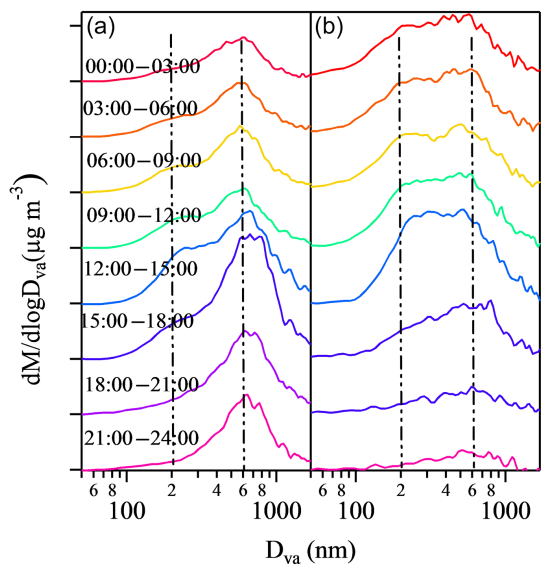

Figure 8. Size distributions of sulfate (a) and organics (b) in different time intervals during E4.
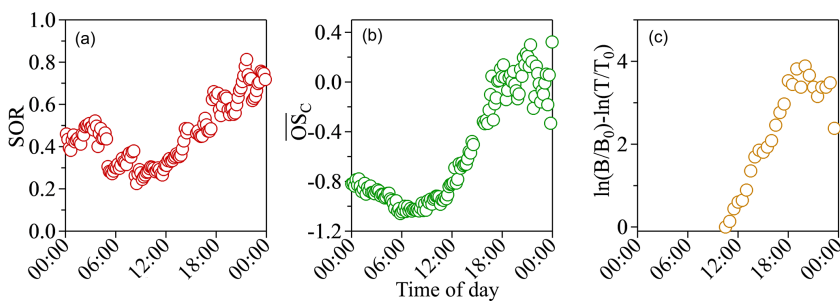

Figure 9. Oxidative evolution of aerosol components. (a) Sulfur oxidation ratio (SOR), (b) average carbon oxidation state $\overline{\mathrm{OS}}_{\mathrm{c}}$, and (c) benzene to toluene ratio ( $B$ : benzene concentration at time $t ; B_{0}$ : benzene concentration at time $0 ; T$ : toluene concentration at time $t$; $T_{0}$ : toluene concentration at time 0 ).

species reflects efficient oxidation during this photochemical episode.

To semi-quantitatively evaluate the efficiency of SOA and sulfate formation, the changes in SOA $/ \Delta \mathrm{CO}$, MSA $/ \Delta \mathrm{CO}$, and sulfate $/ \triangle \mathrm{CO}$ are plotted in Fig. 10 as a function of photochemical age from 10:00 to 18:00 LT. $\triangle \mathrm{CO}$, defined as the measured $\mathrm{CO}$ concentration minus the minimum $\mathrm{CO}$ concentration (see Fig. 7 for the time series of $\mathrm{CO}$ ), is assumed to be a conservative tracer of urban combustion emissions. The perturbations of $\mathrm{CO}$ concentration by photochemical formation from $\mathrm{VOC}$ or destruction by $\mathrm{OH}$ radicals were thought to be negligible over such a short timescale (less than $8 \mathrm{~h}$ ) (Griffin et al., 2007). Normalization of species concentrations to the $\Delta \mathrm{CO}$ concentration is expected to reduce the effect of dilution (Hayes et al., 2013; Zhou et al., 2014).

From 10:00 to $18: 00 \mathrm{LT}$, sulfate / $\triangle \mathrm{CO}$ increased by a factor of 7-8 as photochemical activity increased on a timescale of approximately $6 \mathrm{~h}$, with a formation rate (indicated by the slope of species $/ \triangle \mathrm{CO}$ vs. photochemical age) of approximately $48 \mu \mathrm{g} \mathrm{m}^{-3} \mathrm{ppm}^{-1} \mathrm{~h}^{-1}$. MSA / $\Delta \mathrm{CO}$ also increased by a factor of approximately 3 at a 


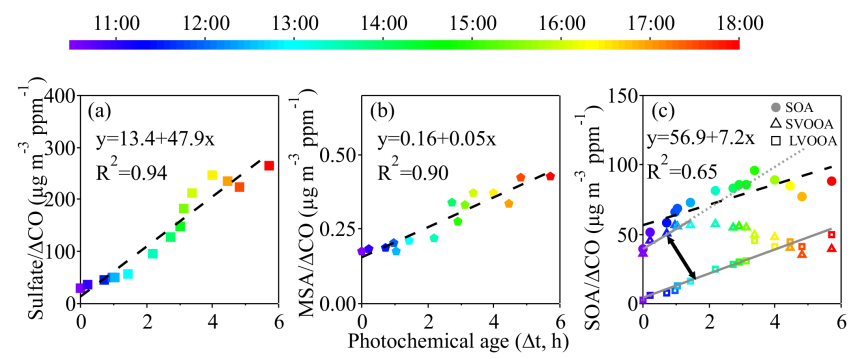

Figure 10. Photochemical production of secondary species. (a) $\mathrm{CO}-$ normalized sulfate concentration (sulfate $/ \triangle \mathrm{CO}$ ) as a function of photochemical age, (b) CO-normalized MSA concentration (MSA / $\triangle \mathrm{CO}$ ) as a function of photochemical age, and (c) COnormalized secondary organic aerosol concentration (SOA / $\triangle \mathrm{CO}$, SOA (SVOOA + LVOOA)) as a function of photochemical age. Data points are colored according to time of day. Data points represent half-hour averages.

rate of $0.05 \mu \mathrm{g} \mathrm{m}^{-3} \mathrm{ppm}^{-1} \mathrm{~h}^{-1}$ during photochemical aging. The good correlation of MSA production with the photochemical age suggests that MSA originated from the reaction of gaseous dimethyl sulfide with $\mathrm{OH}$ radicals (Barnes et al., 2006). For comparison, Bardouki et al. (2003) also found that MSA and OH radicals covaried over the northeastern coast of Crete. As shown in Fig. 10c, SOA $/ \triangle \mathrm{CO}$ increased by approximately a factor of 2 with the slope of $7.2 \mu \mathrm{g} \mathrm{m}^{-3} \mathrm{ppm}^{-1} \mathrm{~h}^{-1}$ $\left(8.07 \mu \mathrm{g} \mathrm{sm}^{-3} \mathrm{ppm}^{-1} \mathrm{~h}^{-1}\right)$. A shallower slope (approximately 4.0 to $4.5 \mu \mathrm{g} \mathrm{sm}^{-3} \mathrm{ppm}^{-1} \mathrm{~h}^{-1}$ ) was observed in Pasadena, California, from May to June (Hayes et al., 2013) while a similar slope $\left(6.18 \mu \mathrm{g} \mathrm{m}^{-3} \mathrm{ppm}^{-1} \mathrm{~h}^{-1}\right)$ was observed in a previous study in Hong Kong in August (Zhou et al., 2014). The SOA production in Hong Kong during the local in situ photochemical oxidation in summer is high.

More interestingly, SVOOA $/ \triangle \mathrm{CO}$ increased during the first $3 \mathrm{~h}$ but decreased slightly after 13:00 LT, even as photochemical age increased. In contrast, LVOOA / $\Delta \mathrm{CO}$ increased steadily throughout the whole stage. After photochemical processing for $6 \mathrm{~h}, \mathrm{LVOOA} / \triangle \mathrm{CO}$ increased by approximately a factor of 20 , from 2.3 to $49.4 \mu \mathrm{g} \mathrm{m}^{-3} \mathrm{ppm}^{-1}$. Even though both SVOOA $/ \Delta \mathrm{CO}$ and LVOOA / $\Delta \mathrm{CO}$ increased in the first stage, they did so at slightly different rates, where SVOOA $/ \triangle \mathrm{CO}$ increased faster than LVOOA $/ \Delta \mathrm{CO}$. This suggests that the production of SVOOA was more efficient than that of LVOOA in the first stage. However, in the later stage of SOA formation, the net productions of SVOOA were negative, which indicates that SVOOA may have photochemically converted to LVOOA. As discussed earlier, the input of POA and VOC was limited to the early morning in our study. SVOOA was consumed more quickly to form LVOOA than was replenished through further production in the late afternoon. The situation where limited precursors exist to replenish fresh SOA (even under strong photochemical activity) might also occur in other non-urban atmospheric en- vironments, and thus may have an implication for OA transformation in general.

\subsubsection{Mass spectral evolution}

Figure 11a shows the evolving organic mass spectra during E4 (corresponding to the period of photochemical aging). Eight spectra at $1 \mathrm{~h}$ intervals from 10:00 to 18:00 LT are shown from top to bottom. Two changes in the mass spectra with photochemical processes were apparent: (1) decreases in the signal intensities of relatively high $m / z$ ions (e.g., $m / z 55,57,67,69$ ), which indicates greater fragmentation $(\mathrm{C}-\mathrm{C}$ bond cleavage) with photochemical oxidation and (2) increases in the mass concentrations of ions having $\mathrm{m} / \mathrm{z}$ values of 28 (mainly $\mathrm{CO}^{+}$) and 44 (mainly $\mathrm{CO}_{2}^{+}$), which presumably come from aldehyde, ketone and carboxylic acid (Ng et al., 2011). These changes are also reflected in the relative intensity changes of hydrocarbon-like and oxygen-containing ions such as $\mathrm{C}_{4} \mathrm{H}_{7}^{+}, \mathrm{C}_{2} \mathrm{H}_{3} \mathrm{O}^{+}$and $\mathrm{CO}_{2}^{+}$(Fig. 11b, c). The fractions of tracers of primary organic aerosols $\mathrm{C}_{3} \mathrm{H}_{7}^{+}(m / z 43), \mathrm{C}_{4} \mathrm{H}_{7}^{+}(m / z 55)$ and $\mathrm{C}_{4} \mathrm{H}_{9}^{+}$ $(m / z$ 57) (Lambe et al., 2012) decreased. On the other hand, ion fractions of $\mathrm{C}_{2} \mathrm{H}_{3} \mathrm{O}^{+}(\mathrm{m} / z 43), \mathrm{C}_{3} \mathrm{H}_{3} \mathrm{O}^{+}(\mathrm{m} / z$ 55) and $\mathrm{C}_{3} \mathrm{H}_{5} \mathrm{O}^{+}(\mathrm{m} / z$ 57) increased until 13:00 LT (corresponding to the peak of SVOOA), followed by the decrease in these moderately oxygenated ions. These ions are predominantly from non-acid oxygenates and are usually associated with less-oxidized SOA. However, the most oxidized ion, $\mathrm{CO}_{2}^{+}$ $(\mathrm{m} / \mathrm{z} 44)$, a marker of more-oxidized SOA, increased continuously. As a result, the mass spectra, which were initially SVOOA-like, evolved to become LVOOA-like with increasing photochemical age (Fig. 11d). Overall, this spectral analysis indicates increasingly oxidized organics, as long carbon chains became more functionalized and fragmented after extensive oxidation (Alfarra et al., 2012; Kroll et al., 2009). Such an observation implies efficient transformation of OA within a few hours of photochemical aging, a timescale that could be relevant to chemical transport models concerning SOA formation.

\section{Conclusion}

High-resolution HR-ToF-AMS measurements were taken during four 1-month campaigns in suburban Hong Kong to illustrate the evolution of high-PM episodic events across the seasons. Three types of episodes - medium-range transport with high particle liquid water content (LWC episodes), medium-range transport with high solar irradiance (IR episodes), and long-range transport (LRT episodes) - were captured based on synoptic meteorological conditions. Which type of episode occurred depended on the season, with LWC episodes occurring only in spring and LRT episodes only in winter, while IR episodes took place throughout the year except in winter. Sulfate was the ma- 


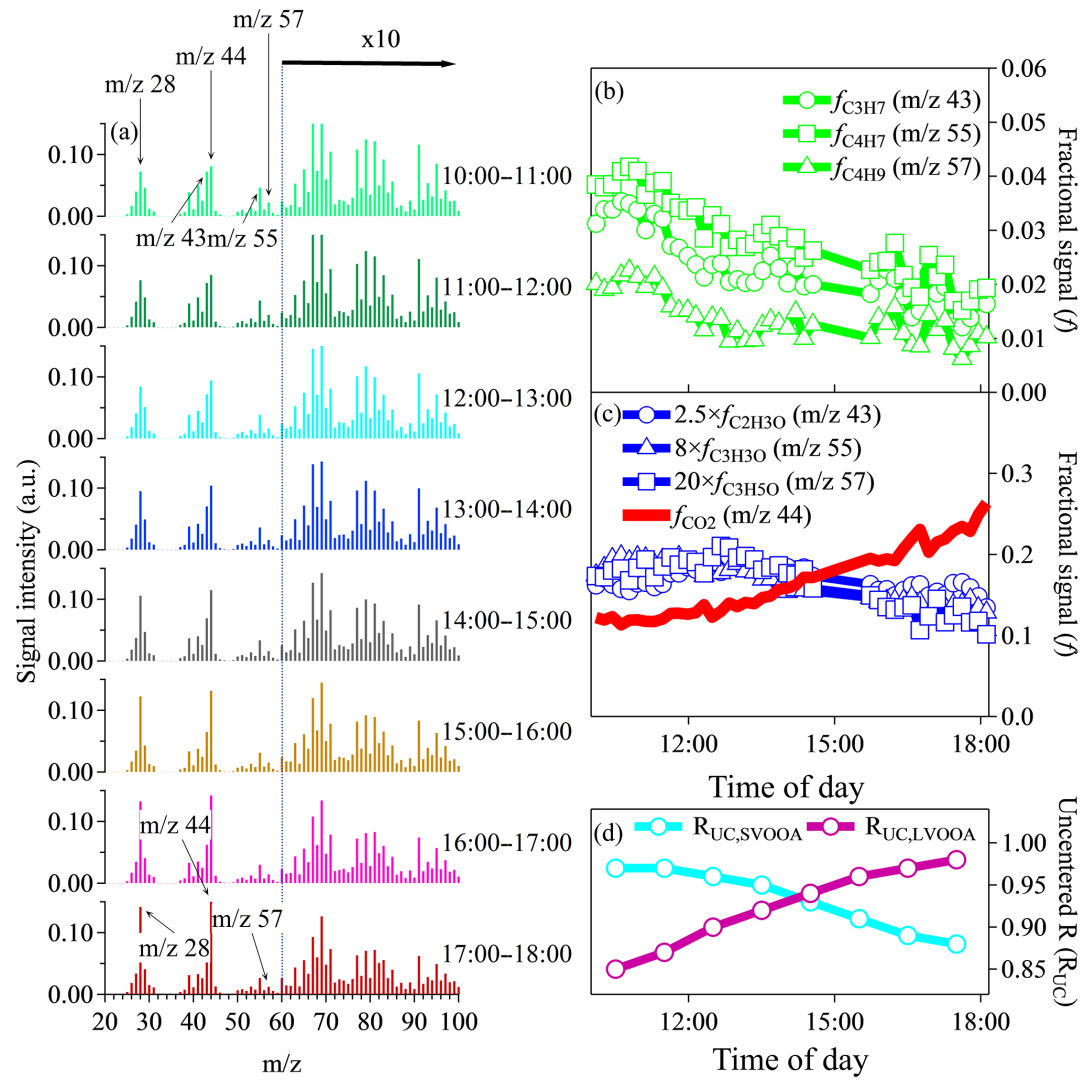

Figure 11. Evolution of high-resolution organic mass spectra from 10:00 to 18:00 LT during the photochemical aging process in E4. (a) Mass spectral evolution; (b) changes in relative intensities of hydrocarbon-like ions: $\mathrm{C}_{3} \mathrm{H}_{7}^{+}(\mathrm{m} / z \quad 43), \mathrm{C}_{4} \mathrm{H}_{7}^{+}\left(\mathrm{m} / z\right.$ 55) and $\mathrm{C}_{4} \mathrm{H}_{9}^{+}(m / z$ 57); (c) changes in relative intensities of oxygen-containing ions: $\mathrm{C}_{2} \mathrm{H}_{3} \mathrm{O}^{+}(m / z 43), \mathrm{C}_{3} \mathrm{H}_{3} \mathrm{O}^{+}(m / z 55), \mathrm{C}_{3} \mathrm{H}_{5} \mathrm{O}^{+}\left(m / z\right.$ 57) and CO${ }_{2}^{+}(m / z 44)$; and (d) correlation of OA mass spectra with reference (Mohr et al., 2012) SVOOA and LVOOA mass spectra.

jor constituent of NR-PM 1 during all episodic events. The contribution of secondary organic species, including SVOOA and LVOOA, varied across episode types, with more SVOOA in the IR episodes and more LVOOA in the LRT episodes. Unlike in the other two types of episodes, in IR episodes organics experienced the most dramatic diurnal variation, with a time lag between SVOOA and LVOOA. This variation was associated with $\mathrm{O}_{x}$, indicating the conversions from lessoxidized to more-oxidized SOA under photochemical oxidation. Elemental analysis involving the Van Krevelen diagram and carbon oxidation state $\left(\overline{\mathrm{OS}}_{\mathrm{c}} \approx 2 \times \mathrm{O}: \mathrm{C}-\mathrm{H}: \mathrm{C}\right)$ further showed that organics in IR were gradually oxidized.

Fitted mass-mode diameters for both the small and the large mode of organics remained roughly constant across episode types, while sulfate had a constant small-mode diameter in all three types of episodes but a slightly increased large-mode diameter in IR episodes. The fraction of small particles decreased from LWC episodes to IR episodes then to LRT episodes, suggesting that aerosols from long-range transport were more aged and dominated by large particles, while episodes under a greater influence of local processes had a higher proportion of fresher small particles.
Large particles mixed internally only in LWC episodes, and were more likely to mix externally in IR and LRT episodes. Freshly formed small particles mixed externally in all types of episodes. In IR episodes, aerosols underwent an obvious size increase, while in LWC episodes the size increase was much less drastic.

Because of the high frequency of IR episodes, we picked one particular IR episode featuring land-sea breeze to examine in detail the evolution of aerosol components. Photochemical aging led to mode size shifting for sulfate and organics, indicating particle growth. Increases in the sulfur oxidation ratio and carbon oxidation state were also observed as the aerosols became more aged, which indicates that secondary inorganic species sulfate and SOA were very efficiently produced within $6 \mathrm{~h}$ of photochemical aging. In the earlier stage of aging, "less-oxidized" SOA (SVOOA) was formed at a higher rate than "more-oxidized" SOA (LVOOA). SVOOA clearly transformed to LVOOA at the later stage of photochemical aging, resulting in a 20-fold increase in LVOOA. This conversion was further supported by mass spectral analysis, which showed an increase in the most oxidized ion $\left(\mathrm{CO}_{2}^{+}\right)$and decreases in moderately oxidized 
ones $\left(\mathrm{C}_{2} \mathrm{H}_{3} \mathrm{O}^{+}, \mathrm{C}_{3} \mathrm{H}_{3} \mathrm{O}^{+}\right.$and $\left.\mathrm{C}_{3} \mathrm{H}_{5} \mathrm{O}^{+}\right)$. With real-time sizeresolved chemical composition data, we demonstrated that aerosol components can transform very efficiently in just a few hours, a process that is essential in understanding the dynamic nature of aerosol evolution during episodes with high PM concentrations.

\section{Data availability}

The data are available upon request. To obtain the data, please contact Chak Keung Chan (chak.k.chan@cityu.edu.hk) or $\quad$ Yong Jie Li (yongjieli@umac.mo).

\section{The Supplement related to this article is available online at doi:10.5194/acp-16-14131-2016-supplement.}

Acknowledgements. This work was supported by the Environmental Conservation Fund of Hong Kong (project number ECWW09EG04) and the Research Grants Council of the Hong Kong Special Administrative Region, China (General Research Fund 600413). Yong Jie Li gratefully acknowledges the support from the Start-up Research Grant (SRG2015-00052-FST) of the University of Macau. The grant from the HKUST Asian Future Leaders Scholarship Program (AFLSP) is also gratefully acknowledged.

Edited by: M. Shiraiwa

Reviewed by: two anonymous referees

\section{References}

Aiken, A. C., Salcedo, D., Cubison, M. J., Huffman, J. A., DeCarlo, P. F., Ulbrich, I. M., Docherty, K. S., Sueper, D., Kimmel, J. R., Worsnop, D. R., Trimborn, A., Northway, M., Stone, E. A., Schauer, J. J., Volkamer, R. M., Fortner, E., de Foy, B., Wang, J., Laskin, A., Shutthanandan, V., Zheng, J., Zhang, R., Gaffney, J., Marley, N. A., Paredes-Miranda, G., Arnott, W. P., Molina, L. T., Sosa, G., and Jimenez, J. L.: Mexico City aerosol analysis during MILAGRO using high resolution aerosol mass spectrometry at the urban supersite (T0) - Part 1: Fine particle composition and organic source apportionment, Atmos. Chem. Phys., 9, 6633-6653, doi:10.5194/acp-9-6633-2009, 2009.

Alfarra, M. R., Hamilton, J. F., Wyche, K. P., Good, N., Ward, M. W., Carr, T., Barley, M. H., Monks, P. S., Jenkin, M. E., Lewis, A. C., and McFiggans, G. B.: The effect of photochemical ageing and initial precursor concentration on the composition and hygroscopic properties of $\beta$-caryophyllene secondary organic aerosol, Atmos. Chem. Phys., 12, 6417-6436, doi:10.5194/acp12-6417-2012, 2012.

Atkinson Roger, J. A.: Atmospheric degradation of volatile methylsilicon compounds, Environ. Sci. Technol., 34, 1970-1976, doi:10.1021/es9910053, 2000.
Bahreini, R., Jimenez, J. L., Wang, J., Flagan, R. C., Seinfeld, J. H., Jayne, J. T., and Worsnop, D. R.: Aircraft-based aerosol size and composition measurements during ACE-Asia using an Aerodyne aerosol mass spectrometer, J. Geophys. Res., 108, 8645, doi:10.1029/2002JD003226, 2003.

Bardouki, H., Berresheim, H., Vrekoussis, M., Sciare, J., Kouvarakis, G., Oikonomou, K., Schneider, J., and Mihalopoulos, N.: Gaseous (DMS, MSA, $\mathrm{SO}_{2}, \mathrm{H}_{2} \mathrm{SO}_{4}$ and DMSO) and particulate (sulfate and methanesulfonate) sulfur species over the northeastern coast of Crete, Atmos. Chem. Phys., 3, 1871-1886, doi:10.5194/acp-3-1871-2003, 2003.

Barnes, I., Hjorth, J., and Mihalapoulos, N.: Dimethyl sulfide and dimethyl sulfoxide and their oxidation in the atmosphere, Chem. Rev., 106, 940-975, doi:10.1021/cr020529+, 2006.

Canagaratna, M. R., Jimenez, J. L., Kroll, J. H., Chen, Q., Kessler, S. H., Massoli, P., Hildebrandt Ruiz, L., Fortner, E., Williams, L. R., Wilson, K. R., Surratt, J. D., Donahue, N. M., Jayne, J. T., and Worsnop, D. R.: Elemental ratio measurements of organic compounds using aerosol mass spectrometry: characterization, improved calibration, and implications, Atmos. Chem. Phys., 15, 253-272, doi:10.5194/acp-15-253-2015, 2015.

Cheung, H. H. Y., Yeung, M. C., Li, Y. J., Lee, B. P., and Chan, C. K.: Relative Humidity-Dependent HTDMA Measurements of Ambient Aerosols at the HKUST Supersite in Hong Kong, China, Aerosol Sci. Technol., 49, 643-654, doi:10.1080/02786826.2015.1058482, 2015.

Cheung, H. H. Y., Tan, H., Xu, H., Li, F., Wu, C., Yu, J. Z., and Chan, C. K.: Measurements of non-volatile aerosols with a VTDMA and their correlations with carbonaceous aerosols in Guangzhou, China, Atmos. Chem. Phys., 16, 8431-8446, doi:10.5194/acp-16-8431-2016, 2016.

Clegg, S. L., Brimblecombe, P., and Wexler, A. S.: Thermodynamic Model of the System $\mathrm{H}^{+}-\mathrm{NH}_{4}^{+}-\mathrm{Na}^{+}-\mathrm{SO}_{4}^{2-}-\mathrm{NO}_{3}^{-}$$\mathrm{Cl}^{-}-\mathrm{H}_{2} \mathrm{O}$ at $298.15 \mathrm{~K}$, J. Phys. Chem. A, 102, 2155-2171, doi:10.1021/jp973043j, 1998.

Decarlo, P. F., Kimmel, J. R., Trimborn, A., Northway, M. J., Jayne, J. T., Aiken, A. C., Gonin, M., Fuhrer, K., Horvath, T., Docherty, K. S., Worsnop, D. R., and Jimenez, J. L.: Field-Deployable, High-Resolution, Time-of-Flight Aerosol Mass Spectrometer, Anal. Chem., 78, 8281-8289, doi:10.1021/ac061249n, 2006.

DeCarlo, P. F., Dunlea, E. J., Kimmel, J. R., Aiken, A. C., Sueper, D., Crounse, J., Wennberg, P. O., Emmons, L., Shinozuka, Y., Clarke, A., Zhou, J., Tomlinson, J., Collins, D. R., Knapp, D., Weinheimer, A. J., Montzka, D. D., Campos, T., and Jimenez, J. L.: Fast airborne aerosol size and chemistry measurements above Mexico City and Central Mexico during the MILAGRO campaign, Atmos. Chem. Phys., 8, 4027-4048, doi:10.5194/acp-84027-2008, 2008.

DeCarlo, P. F., Ulbrich, I. M., Crounse, J., de Foy, B., Dunlea, E. J., Aiken, A. C., Knapp, D., Weinheimer, A. J., Campos, T., Wennberg, P. O., and Jimenez, J. L.: Investigation of the sources and processing of organic aerosol over the Central Mexican Plateau from aircraft measurements during MILAGRO, Atmos. Chem. Phys., 10, 5257-5280, doi:10.5194/acp-10-52572010, 2010.

El Haddad, I., D’Anna, B., Temime-Roussel, B., Nicolas, M., Boreave, A., Favez, O., Voisin, D., Sciare, J., George, C., Jaffrezo, J.-L., Wortham, H., and Marchand, N.: Towards a better understanding of the origins, chemical composition and aging of oxy- 
genated organic aerosols: case study of a Mediterranean industrialized environment, Marseille, Atmos. Chem. Phys., 13, 78757894, doi:10.5194/acp-13-7875-2013, 2013.

Fang, M., Zheng, M., Wang, F., Chim, K., and Kot, S.: The longrange transport of aerosols from northern China to Hong Kong - a multi-technique study, Atmos. Environ., 33, 1803-1817, doi:10.1016/S1352-2310(98)00318-5, 1999.

Griffin, R. J., Chen, J., Carmody, K., Vutukuru, S., and Dabdub, D.: Contribution of gas phase oxidation of volatile organic compounds to atmospheric carbon monoxide levels in two areas of the United States, J. Geophys. Res., 112, D10S17, doi:10.1029/2006JD007602, 2007.

Hagler, G. S. W., Bergin, M. H., Salmon, L. G., Yu, J. Z., Wan, E. C. H., Zheng, M., Zeng, L. M., Kiang, C. S., Zhang, Y. H., Lau, A. K. H., and Schauer, J. J.: Source areas and chemical composition of fine particulate matter in the Pearl River Delta region of China, Atmos. Environ., 40, 3802-3815, doi:10.1016/j.atmosenv.2006.02.032, 2006.

Hayes, P. L., Ortega, A. M., Cubison, M. J., Froyd, K. D., Zhao, Y., Cliff, S. S., Hu, W. W., Toohey, D. W., Flynn, J. H., Lefer, B. L., Grossberg, N., Alvarez, S., Rappenglück, B., Taylor, J. W., Allan, J. D., Holloway, J. S., Gilman, J. B., Kuster, W. C., De Gouw, J. A., Massoli, P., Zhang, X., Liu, J., Weber, R. J., Corrigan, A. L., Russell, L. M., Isaacman, G., Worton, D. R., Kreisberg, N. M., Goldstein, A. H., Thalman, R., Waxman, E. M., Volkamer, R., Lin, Y. H., Surratt, J. D., Kleindienst, T. E., Offenberg, J. H., Dusanter, S., Griffith, S., Stevens, P. S., Brioude, J., Angevine, W. M., and Jimenez, J. L.: Organic aerosol composition and sources in Pasadena, California, during the 2010 CalNex campaign, J. Geophys. Res.-Atmos., 118, 9233-9257, doi:10.1002/jgrd.50530, 2013.

Heald, C. L., Kroll, J. H., Jimenez, J. L., Docherty, K. S., Decarlo, P. F., Aiken, A. C., Chen, Q., Martin, S. T., Farmer, D. K., and Artaxo, P.: A simplified description of the evolution of organic aerosol composition in the atmosphere, Geophys. Res. Lett., 37, L08803, doi:10.1029/2010GL042737, 2010.

Healy, R. M., Sciare, J., Poulain, L., Crippa, M., Wiedensohler, A., Prévôt, A. S. H., Baltensperger, U., Sarda-Esève, R., McGuire, M. L., Jeong, C.-H., McGillicuddy, E., O’Connor, I. P., Sodeau, J. R., Evans, G. J., and Wenger, J. C.: Quantitative determination of carbonaceous particle mixing state in Paris using single-particle mass spectrometer and aerosol mass spectrometer measurements, Atmos. Chem. Phys., 13, 9479-9496, doi:10.5194/acp13-9479-2013, 2013

Healy, R. M., Riemer, N., Wenger, J. C., Murphy, M., West, M., Poulain, L., Wiedensohler, A., O'Connor, I. P., McGillicuddy, E., Sodeau, J. R., and Evans, G. J.: Single particle diversity and mixing state measurements, Atmos. Chem. Phys., 14, 6289-6299, doi:10.5194/acp-14-6289-2014, 2014.

Ho, K., Lee, S., Chan, C. K., Yu, J. C., Chow, J. C., and Yao, X.: Characterization of chemical species in $\mathrm{PM}_{2.5}$ and $\mathrm{PM}_{10}$ aerosols in Hong Kong, Atmos. Environ., 37, 31-39, doi:10.1016/S1352-2310(02)00804-X, 2003.

Hofzumahaus, A., Rohrer, F., Lu, K., Bohn, B., Brauers, T., Chang, C.-C., Fuchs, H., Holland, F., Kita, K., Kondo, Y., Li, X., Lou, S., Shao, M., Zeng, L., Wahner, A., and Zhang, Y.: Amplified trace gas removal in the troposphere, Science, 324, 1702-1704, doi:10.1126/science.1164566, 2009
Hu, D., Bian, Q., Li, T. W. Y., Lau, A. K. H., and Yu, J. Z.: Contributions of isoprene, monoterpenes, $\beta$-caryophyllene, and toluene to secondary organic aerosols in Hong Kong during the summer of 2006, J. Geophys. Res.-Atmos., 113, 1-14, doi:10.1029/2008JD010437, 2008.

Huang, D. D., Li, Y. J., Lee, B. P., and Chan, C. K.: Analysis of Organic Sulfur Compounds in Atmospheric Aerosols at the HKUST Supersite in Hong Kong Using HR-ToF-AMS, Environ. Sci. Technol., 49, 3672-3679, doi:10.1021/es5056269, 2015.

Huang, R.-J., Zhang, Y., Bozzetti, C., Ho, K.-F., Cao, J.-J., Han, Y., Daellenbach, K. R., Slowik, J. G., Platt, S. M., Canonaco, F., Zotter, P., Wolf, R., Pieber, S. M., Bruns, E. A., Crippa, M., Ciarelli, G., Piazzalunga, A., Schwikowski, M., Abbaszade, G., SchnelleKreis, J., Zimmermann, R., An, Z., Szidat, S., Baltensperger, U., El Haddad, I., and Prévôt, A. S. H.: High secondary aerosol contribution to particulate pollution during haze events in China, Nature, 514, 218-222 doi:10.1038/nature13774, 2014.

Huang, X.-F., He, L.-Y., Xue, L., Sun, T.-L., Zeng, L.-W., Gong, Z.-H., Hu, M., and Zhu, T.: Highly time-resolved chemical characterization of atmospheric fine particles during 2010 Shanghai World Expo, Atmos. Chem. Phys., 12, 4897-4907, doi:10.5194/acp-12-4897-2012, 2012.

Huang, X.-F. F., Yu, J. Z., Yuan, Z. B., Lau, A. K. H. H., and Louie, P. K. K. K.: Source analysis of high particulate matter days in Hong Kong, Atmos. Environ., 43, 1196-1203, doi:10.1016/j.atmosenv.2008.10.013, 2009.

Huang, X. H. H., Bian, Q., Ng, W. M., Louie, P. K. K., and $\mathrm{Yu}, \mathrm{J}$. Z.: Characterization of $\mathrm{PM}_{2.5}$ major components and source investigation in suburban Hong Kong: A one year monitoring study, Aerosol Air Qual. Res., 14, 237-250, doi:10.4209/aaqr.2013.01.0020, 2014.

Ji, D., Li, L., Wang, Y., Zhang, J., Cheng, M., Sun, Y., Liu, Z., Wang, L., Tang, G., Hu, B., Chao, N., Wen, T., and Miao, H.: The heaviest particulate air-pollution episodes occurred in northern China in January, 2013: Insights gained from observation, Atmos. Environ., 92, 546-556, doi:10.1016/j.atmosenv.2014.04.048, 2014.

Jimenez, J. L., Canagaratna, M. R., Donahue, N. M., Prevot, A. S. H., Zhang, Q., Kroll, J. H., DeCarlo, P. F., Allan, J. D., Coe, H., Ng, N. L., Aiken, A. C., Docherty, K. S., Ulbrich, I. M., Grieshop, A. P., Robinson, A. L., Duplissy, J., Smith, J. D., Wilson, K. R., Lanz, V. A., Hueglin, C., Sun, Y. L., Tian, J., Laaksonen, A., Raatikainen, T., Rautiainen, J., Vaattovaara, P., Ehn, M., Kulmala, M., Tomlinson, J. M., Collins, D. R., Cubison, M. J., Dunlea, E. J., Huffman, J. A., Onasch, T. B., Alfarra, M. R., Williams, P. I., Bower, K., Kondo, Y., Schneider, J., Drewnick, F., Borrmann, S., Weimer, S., Demerjian, K., Salcedo, D., Cottrell, L., Griffin, R., Takami, A., Miyoshi, T., Hatakeyama, S., Shimono, A., Sun, J. Y., Zhang, Y. M., Dzepina, K., Kimmel, J. R., Sueper, D., Jayne, J. T., Herndon, S. C., Trimborn, A. M., Williams, L. R., Wood, E. C., Middlebrook, A. M., Kolb, C. E., Baltensperger, U., and Worsnop, D. R.: Evolution of organic aerosols in the atmosphere, Science, 326, 1525-1529, doi:10.1126/science.1180353, 2009.

Kleinman, L. I.: Photochemical age determinations in the Phoenix metropolitan area, J. Geophys. Res., 108, 1-14, doi:10.1029/2002JD002621, 2003.

Kroll, J. H., Smith, J. D., Che, D. L., Kessler, S. H., Worsnop, D. R., and Wilson, K. R.: Measurement of fragmentation and functionalization pathways in the heterogeneous oxidation of oxi- 
dized organic aerosol, Phys. Chem. Chem. Phys., 11, 8005-8014, doi:10.1039/b905289e, 2009.

Kroll, J. H., Donahue, N. M., Jimenez, J. L., Kessler, S. H., Canagaratna, M. R., Wilson, K. R., Altieri, K. E., Mazzoleni, L. R., Wozniak, A. S., Bluhm, H., Mysak, E. R., Smith, J. D., Kolb, C. E., and Worsnop, D. R.: Carbon oxidation state as a metric for describing the chemistry of atmospheric organic aerosol, Nat. Chem., 3, 133-139, doi:10.1038/nchem.948, 2011.

Lambe, A. T., Onasch, T. B., Croasdale, D. R., Wright, J. P., Martin, A. T., Franklin, J. P., Massoli, P., Kroll, J. H., Canagaratna, M. R., Brune, W. H., Worsnop, D. R., and Davidovits, P.: Transitions from Functionalization to Fragmentation Reactions of Laboratory Secondary Organic Aerosol (SOA) Generated from the OH Oxidation of Alkane Precursors, Environ. Sci. Technol., 46, 5430-5437, doi:10.1021/Es300274t, 2012.

Lee, B. P., Li, Y. J., Yu, J. Z., Louie, P. K. K., and Chan, C. K.: Physical and chemical characterization of ambient aerosol by HR-ToF-AMS at a suburban site in Hong Kong during springtime 2011, J. Geophys. Res.-Atmos., 118, 8625-8639, doi:10.1002/jgrd.50658, 2013a.

Lee, B. P., Li, Y. J., Flagan, R. C., Lo, C., and Chan, C. K.: Sizing Characterization of the Fast-Mobility Particle Sizer (FMPS) Against SMPS and HR-ToF-AMS, Aerosol Sci. Technol., 47, 1030-1037, doi:10.1080/02786826.2013.810809, 2013b.

Li, Y., Pöschl, U., and Shiraiwa, M.: Molecular corridors and parameterizations of volatility in the chemical evolution of organic aerosols, Atmos. Chem. Phys., 16, 3327-3344, doi:10.5194/acp16-3327-2016, 2016.

Li, Y. J., Lee, B. Y. L., Yu, J. Z., Ng, N. L., and Chan, C. K.: Evaluating the degree of oxygenation of organic aerosol during foggy and hazy days in Hong Kong using high-resolution time-offlight aerosol mass spectrometry (HR-ToF-AMS), Atmos. Chem. Phys., 13, 8739-8753, doi:10.5194/acp-13-8739-2013, 2013.

Li, Y. J., Lee, B. P., Su, L., Fung, J. C. H., and Chan, C. K.: Seasonal characteristics of fine particulate matter (PM) based on highresolution time-of-flight aerosol mass spectrometric (HR-ToFAMS) measurements at the HKUST Supersite in Hong Kong, Atmos. Chem. Phys., 15, 37-53, doi:10.5194/acp-15-37-2015, 2015.

Louie, P., Watson, J., Chow, J., Chen, A., Sin, D., and Lau, A.: Seasonal characteristics and regional transport of PM in Hong Kong, Atmos. Environ., 39, 1695-1710, doi:10.1016/j.atmosenv.2004.11.017, 2005.

Man, H., Zhu, Y., Ji, F., Yao, X., Lau, N. T., Li, Y., Lee, B. P., and Chan, C. K.: Comparison of daytime and nighttime new particle growth at the HKUST supersite in Hong Kong, Environ. Sci. Technol., 49, 7170-7178, doi:10.1021/acs.est.5b02143, 2015.

Mao, J., Ren, X., Brune, W. H., Olson, J. R., Crawford, J. H., Fried, A., Huey, L. G., Cohen, R. C., Heikes, B., Singh, H. B., Blake, D. R., Sachse, G. W., Diskin, G. S., Hall, S. R., and Shetter, R. E.: Airborne measurement of $\mathrm{OH}$ reactivity during INTEX-B, Atmos. Chem. Phys., 9, 163-173, doi:10.5194/acp-9-163-2009, 2009.

Mazzoleni, L. R., Ehrmann, B. M., Shen, X., Marshall, A. G., and Collett, J. L.: Water-Soluble Atmospheric Organic Matter in Fog: Exact Masses and Chemical Formula Identification by Ultrahigh-Resolution Fourier Transform Ion Cyclotron Resonance Mass Spectrometry, Environ. Sci. Technol., 44, 36903697, doi:10.1021/es903409k, 2010.
Meng, J. W., Yeung, M. C., Li, Y. J., Lee, B. Y. L., and Chan, C. K.: Size-resolved cloud condensation nuclei $(\mathrm{CCN})$ activity and closure analysis at the HKUST Supersite in Hong Kong, Atmos. Chem. Phys., 14, 10267-10282, doi:10.5194/acp-1410267-2014, 2014.

Mohr, C., DeCarlo, P. F., Heringa, M. F., Chirico, R., Slowik, J. G., Richter, R., Reche, C., Alastuey, A., Querol, X., Seco, R., Peñuelas, J., Jiménez, J. L., Crippa, M., Zimmermann, R., Baltensperger, U., and Prévôt, A. S. H.: Identification and quantification of organic aerosol from cooking and other sources in Barcelona using aerosol mass spectrometer data, Atmos. Chem. Phys., 12, 1649-1665, doi:10.5194/acp-12-1649-2012, 2012.

Ng, N. L., Canagaratna, M. R., Jimenez, J. L., Chhabra, P. S., Seinfeld, J. H., and Worsnop, D. R.: Changes in organic aerosol composition with aging inferred from aerosol mass spectra, Atmos. Chem. Phys., 11, 6465-6474, doi:10.5194/acp-11-64652011, 2011.

Petäjä, T., Järvi, L., Kerminen, V.-M., Ding, A. J., Sun, J. N., Nie, W., Kujansuu, J., Virkkula, A., Yang, X., Fu, C. B., Zilitinkevich, S., and Kulmala, M.: Enhanced air pollution via aerosol-boundary layer feedback in China., Sci. Rep., 6, 18998, doi:10.1038/srep18998, 2016.

Seinfeld, J. H. and Pandis, S. N.: Atmospheric From Air Pollution to Climate Change, 2nd Edn., Wiley, New Jersey, 474 pp., 2006.

Shiraiwa, M., Yee, L. D., Schilling, K. A., Loza, C. L., Craven, J. S., Zuend, A., Ziemann, P. J., and Seinfeld, J. H.: Size distribution dynamics reveal particle-phase chemistry in organic aerosol formation, P. Natl. Acad. Sci. USA, 110, 11746-11750, doi:10.1073/pnas.1307501110, 2013.

Squizzato, S., Masiol, M., Brunelli, A., Pistollato, S., Tarabotti, E., Rampazzo, G., and Pavoni, B.: Factors determining the formation of secondary inorganic aerosol: a case study in the Po Valley (Italy), Atmos. Chem. Phys., 13, 1927-1939, doi:10.5194/acp13-1927-2013, 2013.

Su, L., Yuan, Z., Fung, J. C. H., and Lau, A. K. H.: A comparison of HYSPLIT backward trajectories generated from two GDAS datasets, Sci. Total Environ., 506-507, 527-537, doi:10.1016/j.scitotenv.2014.11.072, 2015.

Takegawa, N., Miyakawa, T., Kondo, Y., Blake, D. R., Kanaya, Y., Koike, M., Fukuda, M., Komazaki, Y., Miyazaki, Y., Shimono, A., and Takeuchi, T.: Evolution of submicron organic aerosol in polluted air exported from Tokyo, Geophys. Res. Lett., 33, 3-7, doi:10.1029/2006GL025815, 2006.

Volkamer, R., Jimenez, J. L., San Martini, F., Dzepina, K., Zhang, Q., Salcedo, D., Molina, L. T., Worsnop, D. R., and Molina, M. J.: Secondary organic aerosol formation from anthropogenic air pollution: Rapid and higher than expected, Geophys. Res. Lett., 33, L17811, doi:10.1029/2006GL026899, 2006.

Wang, Y., Zhuang, G., Tang, A., Yuan, H., Sun, Y., Chen, S., and Zheng, A.: The ion chemistry and the source of $\mathrm{PM}_{2.5}$ aerosol in Beijing, Atmos. Environ., 39, 3771-3784, doi:10.1016/j.atmosenv.2005.03.013, 2005.

Wang, H., Zhu, B., Zhang, Z., An, J., and Shen, L.: Mixing state of individual carbonaceous particles during a severe haze episode in January 2013, Nanjing, China, Particuology, 20, 16-23, 2015.

Yang, F., Chen, H., Du, J., Yang, X., Gao, S., Chen, J., and Geng, F.: Evolution of the mixing state of fine aerosols during haze events in Shanghai, Atmos. Res., 104/105, 193-201, 2012. 
Yeung, M. C., Lee, B. P., Li, Y. J., and Chan, C. K.: Simultaneous HTDMA and HR-ToF-AMS measurements at the HKUST Supersite in Hong Kong in 2011, J. Geophys. Res.-Atmos., 119, 9864-9883, doi:10.1002/2013JD021146, 2014.

Zhang, Q., Jimenez, J. L., Canagaratna, M. R., Ulbrich, I. M., Ng, N. L., Worsnop, D. R., and Sun, Y.: Understanding atmospheric organic aerosols via factor analysis of aerosol mass spectrometry: A review, Anal. Bioanal. Chem., 401, 3045-3067, doi:10.1007/s00216-011-5355-y, 2011.

Zhang, R., Wang, G., Guo, S., Zamora, M. L., Ying, Q., Lin, Y., Wang, W., Hu, M., and Wang, Y.: Formation of Urban Fine Particulate Matter, Chem. Rev., 115, 3803-3855, doi:10.1021/acs.chemrev.5b00067, 2015.

Zhang, Y. W., Zhang, X. Y., Zhang, Y. M., Shen, X. J., Sun, J. Y., Ma, Q. L., Yu, X. M., Zhu, J. L., Zhang, L., and Che, H. C.: Significant concentration changes of chemical components of $\mathrm{PM}_{1}$ in the Yangtze River Delta area of China and the implications for the formation mechanism of heavy haze-fog pollution., Sci. Total Environ., 538, 7-15, doi:10.1016/j.scitotenv.2015.06.104, 2015.
Zhao, Y., Hallar, A. G., and Mazzoleni, L. R.: Atmospheric organic matter in clouds: exact masses and molecular formula identification using ultrahigh-resolution FT-ICR mass spectrometry, Atmos. Chem. Phys., 13, 12343-12362, doi:10.5194/acp13-12343-2013, 2013.

Zhong, L., Louie, P. K. K., Zheng, J., Yuan, Z., Yue, D., Ho, J. W. K., and Lau, A. K. H.: Science-policy interplay: Air quality management in the Pearl River Delta region and Hong Kong, Atmos. Environ., 76, 3-10, doi:10.1016/j.atmosenv.2013.03.012, 2013.

Zhou, S., Wang, T., Wang, Z., Li, W., Xu, Z., Wang, X., Yuan, C., Poon, C. N., Louie, P. K. K., Luk, C. W. Y., and Wang, W.: Photochemical evolution of organic aerosols observed in urban plumes from Hong Kong and the Pearl River Delta of China, Atmos. Environ., 88, 219-229, doi:10.1016/j.atmosenv.2014.01.032, 2014. 